\title{
Editorial
}

\section{El sistema de aseguramiento de la calidad en educación superior}

Gloria Omaira Bautista Espinel ${ }^{1}$

$E^{1}$ Ministerio de Educación Nacional, ha venido trabajando en la consolidación del Sistema de Aseguramiento de la Calidad de la Educación Superior, el cual abarca los mecanismos, procesos de mejoramiento e integración de metodologías, que permiten a las universidades y entidades de educación superior alcanzar los postulados propuestos por el gobierno nacional, y plasmados en lo que se denomina comúnmente SISTEMA DE CALIDAD, integrado por: REGISTRO CALIFICADO (CONDICIONES MÍNIMAS) y ACREDITACIÓN DE ALTA CALIDAD, el Sistema está conformado por: el Ministerio de Educación Nacional, el Consejo Nacional de Educación Superior (CESU), la Comisión Nacional Intersectorial para el Aseguramiento de la Calidad de la Educación Superior (CONACES), el Consejo Nacional de Acreditación (CNA), el Instituto Colombiano para el Fomento de la Educación Superior (ICFES) y las instituciones de educación superior (IES).

Existen tres componentes básicos que lo integran: a) Información, la cual se obtiene desde el Sistema Nacional de Información de la Educación Superior (SNIES), mediante los Exámenes de Calidad de la Educación Superior (ECAES), el Observatorio Laboral para la Educación (OLE) y del Sistema de Prevención y Análisis de la Deserción en las Instituciones de Educación Superior (SPADIES). b) La Evaluación, mecanismo del sistema que evalúa a estudiantes, programas de pregrado, posgrado e instituciones educativas, en dos momentos diferentes, el primero a cargo de CONACES, ente evaluador de requisitos mínimos que avala la creación de Instituciones de Educación Superior y de programas académicos. El segundo, que es evaluado por el CNA, ente integrado por académicos, designados por el CESU, responsable de emitir concepto sobre la Acreditación de Alta Calidad de instituciones y programas, proceso que es voluntario. c) El Fomento, a cargo del programa de Centros Regionales de Educación Superior (CERES), el cual permite el fortalecimiento institucional, incorporando nuevas tecnologías de información en la educación, (TIC'S), y el acompañamiento brindado a los planes de mejoramiento, integrando elementos técnicos y tecnológicos.

Son claras las diferencias existentes entre la acreditación de alta calidad que es propia del Sistema Nacional de Acreditación y las condiciones mínimas de calidad el Registro Calificado. La primera tiene como premisa y responsabilidad fundamental garantizar a la sociedad que las instituciones que hacen parte de él, cumplen los más altos requisitos de calidad, y que realizan sus propios procesos de evaluación interna centrada en criterios de mejoramiento continuo. Por otra parte el registro calificado, está circunscrito al marco de la regulación, como una herramienta que el estado utiliza para garantizar que los programas puedan prestar sus servicios, sólo si cumplen unas condiciones mínimas de calidad y demás requisitos.

No obstante, al poseer la Calidad en educación un enfoque sistémico, existen aspectos comunes, dentro de los cuales se destaca, la evaluación por pares académicos. El carácter impositivo e ineludible de los juicios de calidad en la acreditación, se da del mismo modo para las condiciones mínimas, en el caso del registro calificado. Esto implica que, el registro calificado y la acreditación son partes integrantes de un proceso de mejoramiento continuo, con momentos de elaboración, que usan mecanismos distintos, dentro de un objetivo global el aseguramiento social de la calidad en la educación superior.

La Universidad Francisco de Paula Santander, considera importante, realizar todo un trabajo encaminado; a la Acreditación en alta calidad de sus programas académicos, proceso que va más adelantado en algunos planes de estudio, trabajo que no ha sido fácil, y que ha requerido la suma de esfuerzos en diversos frentes de trabajo, ya que el sistema plantean unas condiciones obligatorias para la entidad que presenta el programa académico, además de un proceso interno de autoevaluación, cuyo enfoque es determinar la compatibilidad que existe entre el programa y el marco institucional, etapa que requiere recursos físicos y financieros, elementos fundamentales al acceder a esta fase, que es voluntaria; connotación que no le despoja en ningún momento del elevado nivel de rigurosidad y exigencia del mismo.

Para el colectivo universitario; es importante encontrar el significado y darle la lectura apropiada al proceso, ya que es fundamental, no perder de vista el advenimiento de factores del entorno que hacen urgente y perentoria esta tarea, como lo es la rápida expansión del Sistema de Acreditación en los últimos cinco años, el crecimiento de la matrícula universitaria en el país, la Introducción de la Acreditación de Alta Calidad para Maestrías y Doctorados, (como parte de una Política de Fomento a los Posgrados), la internacionalización del Sistema de Acreditación, para la cual existe ya una Institucionalidad Transnacional en Acreditación en América Latina y el Caribe con organismos como RIACES, (Red Iberoamericana de Acreditación de Educación Superior), CSUCA, (Consejo Superior Universitario Centroamericano), SICEVES, (Sistema Centroamericano de Evaluación y Armonización Académica), MERCOSUR y el Sistema Andino, (en proceso de diseño).

En conclusión se abre ante los programas, docentes, estudiantes y egresados un amplio panorama el cual puede potencializarse, una vez, el sistema de calidad logra el reconocimiento internacional, labor que nuestro país viene consolidando desde hace ya 10 años; esto implica que se tiene capacidad y madurez para competir con otros sistemas sólidos, permeables y al intercambio de saberes, experiencias y logros. Este es el eje fundamental de la estrategia de internacionalización de la educación superior, fortalecida por el creciente interés en movilidad de estudiantes y profesores, que se evidencia en el incremento de acuerdos bilaterales, suscritos para el reconocimiento de títulos académicos. La Acreditación, es una labor con la cual Colombia esta comprometida y es una oportunidad de la cual la Universidad puede verse beneficiada, si con el apoyo de todos se logra dar el gran paso. 